\title{
Sosyal Bilgiler Öğretmen Adaylarının Öğretmenlik Mesleğine Yönelik Tutumları İle Sınıf Yönetimi Öz Yeterlilik İnançları Arasındaki İlişkinin İncelenmesi ${ }^{1}$
}

\author{
Zafer Çakmak $^{2} \quad$ Cengiz Taşkıran $^{3} \quad$ İrfan Arıkan $^{4}$
}

Type/Tür:

Research/Araştırma

Received/Geliş Tarihi: March

22/ 22 Mart 2020

Accepted/Kabul Tarihi:

February 12/ 12 Şubat 2021

Page numbers/Sayfa No: 207-

224

Corresponding

Author/İletişimden Sorumlu

Yazar:

c.taskiran@alparslan.edu.tr

\section{$\checkmark$ iThenticate}

This paper was checked for plagiarism using iThenticate during the preview process and before publication. / $\mathrm{Bu}$ çalışma ön inceleme sürecinde ve yayımlanmadan önce iThenticate yazılımı ile taranmıştır.

Copyright $\odot 2017$ by Cumhuriyet University, Faculty of Education. All rights reserved.

\section{$\ddot{O} z$}

Öğretmen adaylarının öğretmenlik mesleğine yönelik tutumları, mesleği icra edecekleri zaman sınıf içindeki yetkinlikleri ve mesleğe yönelik eğilimlerini etkileyen bir konudur. Bu araştırmanın amacı, sosyal bilgiler öğretmen adaylarının sosyal bilgiler öğretmenliği programını tercih etme durumları ile sınıf düzeylerine göre öğretmenlik mesleğine yönelik tutumlarını ve sınıf yönetimi öz yeterlilik inançlarını incelemek ve sosyal bilgiler öğretmen adaylarının öğretmenlik mesleğine yönelik tutumları ile sınıf yönetimi öz yeterlilik inançları arasındaki ilişkiyi ortaya koymaktır. Araştırmanın modeli nicel araştırma türlerinden ilişkisel tarama modelidir. Araştırma örneklemi, Doğu Anadolu Bölgesi'ndeki iki devlet üniversitesinde sosyal bilgiler öğretmenliği programına devam eden toplam 245 öğrenciden oluşmaktadır. Öğretmen adaylarının öğretmenlik mesleğine yönelik tutumları ile sınıf yönetimi öz yeterlilik inançları arasında bir ilişki olup olmadığını test etmek için de Pearson's basit doğrusal korelasyon testi uygulanmıştır. Araştırmaya katılan öğrencilerin \% 65.5'i sosyal bilgiler öğretmenliği programını isteyerek tercih ederken; \% 33.5' i ise sosyal bilgiler öğretmenliği programını istemeyerek tercih etmiştir. Araştırma sonucunda öğretmenlik mesleğini isteyerek tercih eden öğrencilerin öğretmenlik mesleğine yönelik tutumları, programı istemeyerek tercih eden öğrencilerin tutumlarından anlamlı bir derecede daha olumlu olduğu görülmektedir. Sınıf düzeylerine göre ise öğretmenlik mesleğine yönelik tutumlarda anlamlı bir fark olmadığı görülmektedir. Öğretmenlik mesleğini isteyerek tercih eden öğrencilerin sınıf yönetimi öz yeterlilik inançları, programı istemeyerek tercih eden öğrencilerden anlamlı derecede daha yüksek olduğu fakat sınıf düzeylerine göre sınıf yönetimi öz yeterlilik inançlarında anlamlı bir farklılı̆̆ın olmadığı görülmektedir. Sosyal bilgiler öğretmen adaylarının öğretmenlik mesleğine yönelik tutumları ile sınıf yönetimi öz yeterlilik inançları arasında pozitif yönde ve orta düzeyde bir ilişkinin olduğu ortaya çıkmıştır.

Anahtar Kelimeler: Sosyal bilgiler eğitimi, öğretmen adayları, tutum, sınıf yönetimi, öz yeterlilik.

\section{Suggested APA Citation/Önerilen APA Atıf Biçimi:}

Çakmak, Z., Taşkıran, C., \& Arıkan, İ. (2021). Sosyal bilgiler öğretmen adaylarının öğretmenlik mesleğine yönelik tutumları ile sınıf yönetimi öz yeterlilik inançları arasındaki ilişkinin incelenmesi. Cumhuriyet International Journal of Education, 10(1), 207-224. http:/ / dx.doi.org/10.30703/cije.707548

\footnotetext{
1Prof. Dr., Fırat Üniversitesi, Eğitim Fakültesi, Türkçe ve Sosyal Bilimler Eğitimi Bölümü, Elazığ/Türkiye

Prof. Dr., Firat University, Faculty of Education, Department of Turkish and Social Sciences Education, Elazığ/Turkey e-mail: zcakmak@firat.edu.tr ORCID ID: orcid.org/0000-0002-0612-814X

${ }^{2}$ Dr. Öğr. Üyesi, Muş Alparslan Üniversitesi, Eğitim Fakültesi, Türkçe ve Sosyal Bilimler Eğitimi Bölümü, Muş/Türkiye

Assist. Prof. Dr., Muş Alparslan University, Faculty of Education, Department of Turkish and Social Sciences Education, Muş/ Turkey

e-mail: c.taskiran@alparslan.edu.tr ORCID ID: orcid.org/0000-0002-3677-6316.

${ }^{3}$ Arş. Gör., Harran Üniversitesi, Eğitim Fakültesi, Türkçe ve Sosyal Bilimler Eğitimi Bölümü, Şanlıurfa/Türkiye

Research Assistant., Harran University, Faculty of Education, Department of Turkish and Social Sciences Education Şanlıurfa/Turkey e-mail: irfanarikan@harran.edu.tr ORCID ID: orcid.org/0000-0002-1546-4786
} 


\title{
The Examination of Relationship between Attitudes of Pre-service Social Studies Teachers Towards Teaching Profession and Their Self-efficacy Beliefs in Classroom Management
}

\begin{abstract}
The attitudes of pre-service teachers towards the teaching profession is an issue that affects their competencies in the classroom and their tendencies towards the profession when they will perform the profession. The purpose of this study is to examine preference of pre-service social studies teachers for social studies education program and their attitudes towards teaching profession according to their year of study and their classroom management self-efficacy beliefs and to reveal the relationship between their attitudes towards teaching profession and their classroom management self-efficacy beliefs. The model of the research is the relational screening model, one of the quantitative research types. The research sample consists of a total of 245 students attending social studies education programs at two public universities in the Eastern Anatolia Region. Pearson's simple linear correlation test was applied to test whether there is a relationship between the attitudes of pre-service teachers towards the teaching profession and their classroom management self-efficacy beliefs. While $65.5 \%$ of the students participating in the research preferred the social studies education program willingly, $33.5 \%$ of them preferred the social studies education program undesirably. As a result of the research, it is seen that the attitudes of the students who preferred the teaching profession willingly are more positive than those of the students preferring the program undesirably to a significant extent. No significant difference is observed in the attitudes towards teaching profession according to their year of study. Class management self-efficacy beliefs of students who preferred teaching profession willingly are seen to be higher than those of the ones undesirably preferring the program to a significant extent, but there is no significant difference in classroom management selfefficacy beliefs according to year of study. It was also revealed that there is a positive and moderate relationship between the attitudes of pre-service social studies teachers towards teaching profession and their classroom management self-efficacy beliefs.
\end{abstract}

Keywords: Social studies education, pre-service teachers, attitude, classroom management, self-efficacy

\section{Giriş}

Bir ülkenin gelişmesinde, kalkınmasında eğitim sisteminin çok önemli bir rolü vardır. Eğitim sistemi çok boyutlu bir süreçtir. Fiziki alt yapı, bilgi ve iletişim teknolojilerindeki gelişmelerin eğitime entegre edilmesi, aile katılımı, politik kararlar başta olmak üzere birçok etken eğitimin kalitesinde önemli bir rol oynamaktadır. Fakat hiçbiri öğretmenin kalitesi ile karşılaştırılamaz. Çünkü öğretmen eğitimin ve öğretimin ana aktörlerinden biridir. Bu nedenle geçmişten günümüze öğretmen mesleği ve öğretmenlerin eğitimi ülkelerin gündemlerini meşgul etmiştir. Türkiye için de bu kaidenin geçerli olduğunu görmekteyiz. Zaman zaman karar almakla yetkili mecraların öğretmenlik mesleğine yönelik çalışma yaptıklarını görmekteyiz. Bu çalışmaların temel amacı öğretmen kalitesini arttırmak ve mesleğe yönelik sorunların çözümüne ilişkin kararlar almaktır.

Öğretmenlik mesleği bilgi, beceri, tutum ve değerleri kapsayan uzmanlık gerektiren bir meslektir. Öğretmenler alan bilgisinin yanında mesleki bilgi ve beceriye sahip olması gerekmektedir. Bununla birlikte milli, manevi, ahlaki ve evrensel değerleri içselleştirmiş olması istenmektedir. Mesleki niteliklerin yanında sabırlı olma, 
sevecen olma ve hoşgörülü olma gibi öğretmenlerin sahip olması gereken kişisel nitelikler de vardır.

Her bir öğrencinin kendine özgü kişilik özellikleri, sorunları, değerleri ve önbilgileri olduğu, bu bireysel farklılıkların yanı sıra içinde bulundukları yaş döneminden kaynaklanan sorunlara sahip olduklarını ifade eden Erden (1998); aynı zamanda öğretmenlerin, bu zor görevin üstesinden gelmek için mesleki niteliklerin yanında kişisel özelliklere de sahip olması gerektiğini de belirtmektedir. Bir kişi alana özgü yeterli bilgiye ve beceriye sahip olsa bile, şayet mesleğin gerektirdiği kişisel özelliklere sahip değilse öğretmenlik mesleğinde başarılı olması düşünülemez. Kuran (2002) öğretmenlik mesleğini görev bilinci ve özveriyle pek çok rolü üstlenen ve diğer meslekler arasında ön sırayı oluşturan bir meslek alanı olarak ifade etmektedir. Bu nedenle öğretmenlik, toplumda pek çok role sahip olduğundan kutsal ve saygın bir meslek olarak görülmektedir.

Yukarıdaki tanımlardan da anlaşılacağı üzere öğretmenlik mesleği profesyonel bir meslek olmanın yanında sevgi, merhamet, sayg1 ve sevecen olmak gibi duyuşsal özellikleri de kapsayan bir meslektir. Baykara Pehlivan (2008), öğretmenden beklenen rolleri yerine getirmesinde önemli bir değişken olan öğretmenlik mesleğine yönelik tutumun incelenmesi gerektiğini ifade etmektedir. Bu bağlamda araştırmanın odak noktalarından biri sosyal bilgiler eğitimi alan öğretmen adaylarının öğretmenlik mesleğine yönelik tutumlarıdır.

Öğretmenlerin öğretimi planlama, öğrenme ve öğretme süreçleri, ders diş1 öğretim, ölçme ve değerlendirme, sosyal etkinlik düzenleme olmak üzere birçok sorumluluğu vardır. Fakat öğretim büyük ölçüde sınıfta gerçekleşmekte ve öğretmenin zamanının büyük bir bölümü sınıfta geçmektedir. Bu doğrultuda bu mesleği yapacak bireylerde bulunması gereken önemli bir beceri de sınıf yönetimidir. Balay (2015), sınıf yönetimini, sınıfta gerçekleşen öğretimin etkili olabilmesi için sınıfın, öğrencilerle birlikte yönetilmesi olarak ifade etmektedir. Bu nedenle bir öğretmende olması gereken en önemli becerilerden biri, sınıf yönetimidir. Bir öğretmenin sınıf yönetiminde başarılı olması için birçok değişken vardır. $\mathrm{Bu}$ değişkenler öğretmen öğrenci ilişkileri, öğretmen veli ilişkileri, olumlu öğretmen tutum ve davranışları olarak ifade edilebilir. Bununla birlikte sınıf yönetimi etkileyen başka değişkenlerde vardır. Sınıfın büyüklüğü, yerleşim düzeni, görünüm, ses, 1şık gibi genellikle eğitim ortamından kaynaklanan değişkenlerdir. Fakat başarılı bir öğretmen göstereceği çaba ile fiziksel ortamla ilgili eğitimin kalitesini arttıracak değişimlere neden olabilir.

Günümüzde öğretmenin geleneksel rolleri değişmektedir. Bilginin inanılmaz bir hızla çoğaldığı bir dünyada öğretmenin alanıyla ilgili bütün bilgilere sahip olması mümkün değildir. Artık öğretmenlerden bildiklerini öğrencilere aktarmaktan ziyade öğrenmeyi öğreten ve öğrenmeyi yönlendiren bir kişi olmaları beklenmektedir. Öğrencilere kılavuzluk etmesi ve onları yönlendirmesi gereken öğretmenin bunları yapabilmek için sınıf yapısını ve sınıf ortamını iyi düzeyde algılaması, öğrencileri hakkında bilgi sahibi olması ve onları yönetebilmesi gerekmektedir (Demirtaş, 2012). Değişen bu rollere öğretmen adaylarının hazır olması gerekmektedir. Dolayısıyla bir öğretmen adayının sınıf yönetimi öz yeterliliğine sahip olması gerekmektedir. Sınıf yönetimi öz yeterliliğine sahip olması için de öğretmen adayının sınıf yönetimi öz 
yeterlilik inancına sahip olması gerekmektedir. Araştırmanın ikinci önemli odak noktası da sosyal bilgiler öğretmen adaylarının sınıf yönetimi öz yeterlilik inançlarıdır.

\section{Araştırmanın Önemi}

Araştırmanın önemini ortaya koymak amaçlı gerçekleştirilen alan yazın taramasında, öğretmen adaylarının Öğretmenlik Mesleğine Yönelik Tutumlar (ÖMYT) (Çapa ve Çil, 2000; Akkaya, 2009; Aksoy, 2010; Özder, Konedralı ve Perkan Zeki, 2010) ve spesifik olarak sosyal bilgiler öğretmen adaylarının tutumlarına (Dönmez ve Uslu, 2013; Ünlü, Kaşkaya ve Kızılkaya, 2017; Çiftçi ve Dikmenli, 2015) yönelik çalışmalar yer almaktadır. Yine literatüre bakıldığında öğretmen adaylarının Sınıf Yönetimi Öz Yeterlilik İnançlarını (SYÖI) veya algılarını ölçen çalışmalar (Ekici, 2008; Arsal, 2014; Şahin Sak, 2015) olduğu görülmektedir. Fakat sosyal bilgiler öğretmen adaylarının ÖMYT ile SYÖİ arasında ilişkiyi ölçen herhangi bir araştırmaya da rastlanılmamıştır. Bir öğretmenin başarısında SYÖI'nin önemli bir değişken olarak kabul edildiği göz önünde bulundurulduğunda ve ÖMYT'nin sınıf yönetimi öz yeterlilik inançlarının önemli bir yordayıcısı olarak kabul edildiği göz önünde bulundurulduğunda böyle bir çalışmanın yapılması önem arz etmektedir. Bu bağlamda araştırmanın problemini sosyal bilgiler öğretmen adaylarının öğretmenlik mesleğine yönelik tutumları ile sınıf yönetimi öz yeterlilik inançları oluşturmaktadır. Aşağıda ise araştırmanın alt problemlerine yer verilmiştir:

1. Sosyal bilgiler öğretmen adaylarının mesleği isteyerek veya istemeyerek tercih etme durumlarına ve sınıf düzeylerine göre ÖMYT farklılaşmakta mıdır?

2. Sosyal bilgiler öğretmen adaylarının mesleği isteyerek veya istemeyerek tercih etme durumlarına ve sinıf düzeylerine göre SYÖİ farklılaşmakta mıdır?

3. Sosyal bilgiler öğretmen adaylarının ÖMYT ile SYÖİ arasında anlamlı bir ilişki var midır?

\section{Yöntem}

Araştırma nicel araştırma türlerinden ilişkisel tarama deseninde gerçekleştirilmiştir. $\mathrm{Bu}$ model, iki veya daha fazla değişken arasında ilişkinin varlığı ve düzeyini belirlemeye yönelik gerçekleştirilen nicel araştırma modellerinden biridir (Karasar, 2016). İlişkisel tarama araştırmaları yordayıcı ve keşfedici olabilirken aynı zamanda değişkenler arasındaki ilişkileri ve ilişkilerin yönünü de ortaya koymada yardımcı olur (Sönmez ve Alacapınar, 2017). Araştırma, sosyal bilgiler öğretmen adalarının öğretmenlik mesleğine yönelik tutumları ile sınıf yönetimi öz yeterlik inançları arasında anlamlı bir ilişki olup olmadığı yönünde olduğu için yöntem olarak bu desen tercih edilmiştir.

\section{Evren ve Örneklem}

Araştırmanın evrenini Türkiye'deki yükseköğretim kurumlarında öğrenim gören sosyal bilgiler öğretmen adayları oluşturmaktadır. Örneklem seçimi yapılırken ulaşılabilirlik göz önünde bulundurularak Doğu Anadolu Bölgesindeki üniversiteler araştırmaya dâhil edilmiştir. Bu doğrultuda bu üniversiteler arasından amaçlı örnekleme yöntemlerinden tipik durum örneklemesi yapılarak örneklem, 2019-2020 eğitim öğretim yılı güz döneminde Doğu Anadolu Bölgesindeki Muş Alparslan Üniversitesi ve Furat Üniversitesi'ndeki sosyal bilgiler öğretmenliği programında okuyan öğretmen adayları ile oluşturulmuştur. Tipik durum örnekleme yönteminde 
araştırma probleminin evrendeki çok sayıda örneğini tipik olarak yansıtan grupların seçilmesi söz konusudur (Büyüköztürk vd. 2018). Aşağıda yer alan Tablo 1' de katılımcılara ait bilgiler yer almaktadır.

Tablo 1.

Katılimcilara Ait Bilgiler

\begin{tabular}{llllll}
\hline Cinsiyet & Sinif-1 & Sinif-2 & Sinif-3 & Sinif-4 & Toplam \\
\hline Erkek & 33 & 16 & 31 & 17 & 97 \\
Kadın & 37 & 31 & 45 & 35 & 148 \\
\hline Toplam & 70 & 47 & 76 & 52 & 245 \\
\hline
\end{tabular}

Tablo 1 incelendiğinde 97 erkek, 148 kadın olmak üzere araştırmaya toplam 254 öğrencinin katıldığı görülmektedir. Kadın katılımcı sayısının yüksek olmasının nedeni ise kadınların öğretmenlik mesleğini erkeklere göre daha çok tercih etmesinden kaynaklanmaktadır. Katılımcıların \%28.58'ini birinci sınıf, \%19.18'ini ikinci sınıf, \%31.02'sini üçüncü sınıf ve \%21.22'sini dördüncü sınıf öğrencileri oluşturmaktadır. Katılımin 1. ve 2.sınıflarda yüksek olduğu görülmektedir.

Aşağıda yer alan Tablo 2'de sosyal bilgiler öğretmenliği programina kayıtlı öğrencilerin, sosyal bilgiler öğretmenliği programını isteyerek tercih edip etmediklerine ilişkin bilgiler verilmektedir.

Tablo 2.

Katılımcıların Sosyal Bilgiler Öğretmenlik Programına Yönelik Tercihleri

\begin{tabular}{lll}
\hline Sosyal Bilgiler Öğretmenliği Programına isteyerek mi kaydoldunuz? & $\begin{array}{l}\text { Frekans } \\
\text { (f) }\end{array}$ & Yüzde (\%) \\
\hline Evet & 163 & 66.5 \\
Hayır & 82 & 33.5 \\
\hline Toplam & 245 & 100 \\
\hline
\end{tabular}

Tablo 2 incelendiğinde katılımcı öğretmen adaylarının \% 66.5'inin sosyal bilgiler öğretmenliği programına isteyerek kaydolduğu, öğrencilerin \% 33.5'inin ise sosyal bilgiler öğretmenliği programına isteyerek kaydolmadığı görülmektedir.

\section{Veri Toplama Araçları}

$\mathrm{Bu}$ araştırmada sosyal bilgiler öğretmen adaylarının öğretmenlik mesleğine yönelik tutumlarını ölçmek için; Kahramanoğlu, Yokuş, Cücük, Vural ve Şiraz (2018) tarafından geliştirilmiş olan Öğretmenlik Mesleğine Yönelik Tutum Ölçeği (ÖMYTÖ) kullanılmıştır. Öğretmen adaylarına yönelik geliştirilen bu ölçek, toplam varyansın \% 57.597'sini açıklamaktadır. Sosyal bilgiler öğretmen adaylarının sınıf yönetimi öz yeterlilik inançlarını ölçmek için Çetin (2013) tarafından geliştirilen Sınıf Yönetimi Öz Yeterlilik İnançları Ölçeği (SYÖYİÖ) kullanılmıştır. Ölçekler kullanılmadan önce her iki sorumlu yazardan izin alınmıştır. Bununla birlikte araştırmada öğrencilerin demografik bilgilerinin yer aldığı bir bilgi formu da kullanılmıştır.

Analizler sonucunda öğretmenlik ÖMYTÖ’́nin güvenirlik (iç tutarlılık) katsayısı olan Cronbach's Alpha değeri 0.89 olarak; SYÖYİÖ'nin güvenirlik (iç tutarlılık) katsayı olan Cronbach's Alpha değeri 0.75 olarak hesaplanmıştır. Kılıç'ın “Cronbach'ın Alfa 
Güvenirlik Katsayısı" adlı çalışmasına göre (2016) bu değerler ölçeklere ait sonuçların güvenilir olduğunu göstermektedir.

\section{Veri Toplama Süreci}

Veri toplama araçları öncelikle iki alan uzmanına, iki ölçme ve değerlendirme uzmanına ve iki Türk Dili uzmanına incelettirilmiştir. Uzmanlardan gelen dönütler çerçevesinde veri toplama araçlarına son şekli verilmiştir. Etik kurul raporu olmak üzere gerekli izinler alındıktan sonra veri toplama araçları çoğaltılmıştır. Araştırma gönüllülük esasına dayalı olup araştırma öncesinde katılımcılar bilgilendirilmiştir. Araştırma eğitim öğretim faaliyetlerini aksatmayacak bir şekilde sınıfta gerçekleştirilmiş olup katılımcılara veri toplama araçlarını doldurmaları için yeterli süre verilmiştir.

\section{Verilerin Analizi}

Sosyal bilgiler öğretmen adaylarının sosyal bilgiler öğretmenliği programını isteyerek tercih etme durumları ve sınıfları göz önünde bulundurulduğunda ÖMYT ile SYÖYİ arasında bir fark olup olmadığı test etmek için öncelikle verilerin normalliğine ve varyanslarının homojenliğine bakılmıştır.

ÖMYTÖ ait veriler normal dağılmadığı için sosyal bilgiler öğretmen adaylarının öğretmenlik mesleğini isteyerek tercih edip etmeme durumlarına göre öğretmenlik mesleğine yönelik tutumlarında anlamlı bir farklılık olup olmadı̆̆ını test etmek için Mann-Whitney U testi, sınıf düzeyine göre bir farklılaşmanın söz konusu olup olmadığını test etmek amacıyla da Kruskal-Wallis testi uygulanmıştır.

SYÖYİ ait veriler normal dağıldığı için ve varyansların homejen olması koşulunu sağladığı için, sosyal bilgiler öğretmen adaylarının öğretmenlik mesleğini isteyerek tercih edip etmeme durumlarına göre sınıf yönetimi öz yeterlilik inançları arasında anlamlı bir farklılaşmanın varlığını veya yokluğunu tespit etmek için ilişkisiz örneklemler için $t$ testi, sınıf değişkeninde göre bir farklılaşmanın varlığını veya yokluğunu test etmek için de tek yönlü varyans analizi testi gerçekleştirilmiştir. Öğretmen adaylarının ÖMYT ile SYÖYİ arasında bir ilişki olup olmadığını test etmek için de Pearson's basit doğrusal korelasyon testi uygulanmıştır.

Aşağıda yer alan Tablo 3' de verilerin normal olup olmadığını gösteren çarpıklık ve basıklık değerleri gösterilmiştir.

George ve Mallerry (2003)'e göre; dağılımın normal olması için çarpıklık (skewness) ve basıklık (kurtosis) değerleri -2 ile +2 arasında olması gerekmektedir. 
Tablo 3.

Verilerin Çarpıklık ve Basıklık Değerleri

\begin{tabular}{|c|c|c|c|}
\hline Ölçek & Sinif & Çarpıklık & Basıklık \\
\hline \multirow{4}{*}{ ÖMYT } & 1 & $-1,715$ & 2,726 \\
\hline & 2 & $-1,789$ & 4,173 \\
\hline & 3 & $-1,442$ & 3,729 \\
\hline & 4 & $-1,158$ & 1,513 \\
\hline Ölçek & Tercih durumu & Çarpıklık & Basıklık \\
\hline \multirow{2}{*}{ ÖMYT } & Evet & $-1,983$ & 4,815 \\
\hline & Hayır & $-1,309$ & 2,598 \\
\hline Ölçek & Sinif & Çarpıklık & Basıklık \\
\hline \multirow{4}{*}{ SYÖYİ } & 1 &,- 507 & ,915 \\
\hline & 2 & 161 & 620 \\
\hline & 3 &,- 280 &,- 487 \\
\hline & 4 &,- 297 &,- 123 \\
\hline Ölçek & Tercih durumu & Çarpıklık & Basıklık \\
\hline \multirow{2}{*}{ SYÖYİ } & Evet &,- 084 & 093 \\
\hline & Hayır &,- 507 & ,366 \\
\hline
\end{tabular}

\section{Bulgular}

Sosyal bilgiler öğretmen adaylarının öğretmenlik mesleğini isteyerek tercih edip etmeme durumuna göre ÖMYT'ye ilişkin betimsel istatistik sonuçları ve MannWhitney U testi sonuçları Tablo 4 ve Tablo 5 ' de gösterilmektedir.

Tablo 4 .

Tercih Durumlarna Göre ÖMYT Sonuçlan

\begin{tabular}{lllll}
\hline Ölçek & Grup & $\mathbf{N}$ & Ortalama & SD \\
\hline \multirow{2}{*}{ ÖMYT } & Evet & 163 & 50.325 & 8.428 \\
& Hayır & 82 & 47.049 & 8.517 \\
\hline
\end{tabular}

Tablo 4 incelendiğinde sosyal bilgiler öğretmenlik programını isteyerek tercih eden öğrencilerin ÖMYT'ye ilişkin sıra ortalaması 50.325 iken sosyal bilgiler öğretmenlik programını istemeyerek tercih eden öğrencilerin ÖMYT'ye ilişkin sıra ortalaması 47.049'dur. Bu durum için, sosyal bilgiler öğretmenlik programını isteyerek ve istemeyerek tercih eden öğretmen adayları arasında ÖMYT'de bariz bir farklılık bulunmadığı söylenebilir. Bunun sebebi; sosyal bilgiler öğretmenliği programını istemeyerek tercih edenlerin öğretmenlik mesleğine karşı olumsuz bir tutum içerisinde oldukları için değil, sosyal bilgiler eğitimi alanına karşı bir olumsuz tutum içerisinde oldukları için programa istekle kaydolmamış olma ihtimali olabilir.

Tablo 5.

Tercih Durumlarnna Göre ÖMYT Mann-Whitney U Testi Sonuçları

\begin{tabular}{llllll}
\hline Ölçek & Test & U & Df & p & Cohen's d \\
\hline ÖMYT & Mann-Whitney U & 8654.500 & 243.000 & $<.005$ & 0.295 \\
\hline
\end{tabular}


Sosyal bilgiler öğretmen adaylarının sosyal bilgiler öğretmenlik programını isteyerek tercih edip etmeme durumuna göre ÖMYT'de anlamlı bir fark olup olmadığını test etmek için yapılan Mann-Whitney U testinin sonucuna göre, programı isteyerek tercih eden öğrencilerin ÖMYT'leri, programı istemeyerek öğrencilerin öğretmenlik mesleğine yönelik tutumlarına göre anlamlı derecede farklılaşmaktadır (U=8654.500, $p<0.005)$. Bu farkın sosyal bilgiler öğretmenlik programını isteyerek tercih eden öğrencilerin lehine olduğu görülmektedir. Bu farkın etki büyüklüğü Cohen's d 0.295 olarak hesaplanmıştır. Green ve Salkind' e göre bu farkın etki büyüklüğünün düşük düzeyde olduğu söylenebilir.

Sosyal bilgiler öğretmen adaylarının sınıf değişkeni baz alınarak öğretmenlik mesleğine yönelik tutumlarını belirlemek için yapılan betimsel istatistik sonuçları Tablo 6'da ve Kruskal-Wallis testi sonuçları Tablo 7' de gösterilmektedir.

Tablo 6.

Sinıf Değiş̧kenine Göre ÖMYT Sonuçları

\begin{tabular}{llll}
\hline Sınıf & Ortalama $(\overline{\mathrm{X}})$ & SD & $\mathbf{N}$ \\
\hline 1. sinif & 47.614 & 10.194 & 70 \\
2. sinif & 49.872 & 8.662 & 47 \\
3. sinif & 49.697 & 7.329 & 76 \\
4. sinif & 50.135 & 7.744 & 52 \\
\hline
\end{tabular}

Tablo 6 incelendiğinde sınıf değişkenine göre birinci sınıfın ortalaması ( $\bar{X}=$ 47.614), ikinci sınıfın ortalaması ( $\bar{X}=49.872)$, üçüncü sınıfın ortalaması ( $\bar{X}=49.697)$ ve dördüncü sınıfın ortalamasının $(\bar{X}=50.135)$ olduğu görülmektedir. Bu sonuçlara göre sınıflar arasındaki öğretmenlik mesleğine yönelik tutumda benzer ortalamalar olduğu ve dolayısıyla sınıf değişkeninin öğretmenliğe yönelik tutumda etkili olmadı̆̆ söylenebilir.

Tablo 7.

Sinıf Değişkenine Göre ÖMYT Yönelik Kruskal-Wallis Testi Sonuçları

\begin{tabular}{llll}
\hline Faktör & Chi-square & df & p \\
Sinif & 2.263 & 3 & 0.520 \\
\hline
\end{tabular}

Sosyal bilgiler öğretmen adaylarının sınıf değişkenine göre ÖMYT’leri arasında anlamlı bir farklılaşma olup olmadı̆̆ını tespit etmek amacıyla yapılan Kruskal-Wallis testi sonuçlarına göre; birinci, ikinci, üçüncü ve dördüncü sınıf olmak ÖMYT üzerinde anlamlı bir fark oluşturmamaktadır. Bu sonuç, aritmetik ortalama sonuçları ile birbirini desteklemektedir.

Sosyal bilgiler öğretmen adaylarının sosyal bilgiler öğretmenlik programını isteyerek tercih edip etmeme durumuna göre SYÖYI'lerine ilişkin betimsel istatistik sonuçları Tablo 8'de ve bağımsız gruplar için t testi sonuçları Tablo 9'da gösterilmektedir. 
Tablo 8.

Tercih Durumlarna Göre SYÖYİ Sonuçlan

\begin{tabular}{lllll}
\hline Ölçek & Grup & $\mathbf{N}$ & $\overline{\mathbf{X}}$ & SD \\
\hline SYÖYİ & Evet & 163 & 57.0316 .957 \\
& Hayır & 82 & 54.9888 .502 \\
\hline
\end{tabular}

Tablo 8 incelendiğinde sosyal bilgiler öğretmenlik programını isteyerek tercih eden öğrencilerin sınıf yönetimi öz yeterlilik inançları ortalaması ( $\bar{X}=57.031)$, iken sosyal bilgiler öğretmenlik programını istemeyerek tercih eden öğrencilerin SYÖYİ ortalamasi $(\overline{\mathrm{X}}=54.988)^{\prime}$ dir.

Tablo 9.

Tercih Durumlarnna SYÖYİ İlişkisiz Örneklemler İçin T Testi Sonuçları

\begin{tabular}{lllll}
\hline Ölçek & $\mathbf{t}$ & $\mathbf{d f}$ & $\mathbf{p}$ & Cohen's $\mathbf{d}$ \\
\hline SYÖYİ & 2.010 & 243.000 & 0.046 & 0.272 \\
\hline
\end{tabular}

Sosyal bilgiler öğretmen adaylarının sosyal bilgiler öğretmenlik programını isteyerek tercih edip etmeme durumuna göre SYÖYI'leri arasında anlamlı bir fark olup olmadığını test etmek amacıyla yapılan ilişkisiz örneklemler için t testi sonucuna göre; sosyal bilgiler öğretmenlik programını isteyerek tercih eden sosyal bilgiler öğretmen adaylarının sınıf yönetimi öz yeterlilik inançları $(\bar{X}=57.073)$ ile sosyal bilgiler öğretmenlik programını isteyerek tercih etmeyen sosyal bilgiler öğretmen adaylarının sınıf yönetimi öz yeterlilik inançları $(\bar{X}=54.988)$ arasında anlamlı bir fark görülmektedir $\left(t_{243}=2.010, \mathrm{p}<0.05\right)$. Bu anlamlı farkın sosyal bilgiler öğretmenlik programını isteyerek tercih eden öğretmen adaylarının lehine olduğu görülmektedir. Bu farkın etki büyüklüğü Cohen's d 0.272 olarak hesaplanmıştır Green ve Salkind' e göre bu farkın etki büyüklüğünün düşük düzeyde olduğu söylenebilir.

Sosyal bilgiler öğretmen adaylarının sınıf değişkenine göre sınıf yönetimi öz yeterlilik inançlarına ilişkin betimsel istatistik sonuçları Tablo 9' da ve tek yönlü varyans analizi sonuçları Tablo 10'da gösterilmektedir.

Tablo 10.

Sinıf değişkenine göre SYÖYİ sonuçları

\begin{tabular}{lcll}
\hline SINIF & $\overline{\mathbf{X}}$ & SD & $\mathbf{N}$ \\
\hline Sinif-1 & 54.586 & 8.348 & 70 \\
Sinif-2 & 56.362 & 6.462 & 47 \\
Sinif-3 & 57.092 & 6.806 & 76 \\
Sinif-4 & 57.615 & 8.136 & 52 \\
\hline
\end{tabular}

Tablo 10 incelendiğinde sınıf değişkenine göre birinci sınıftaki öğretmen adaylarının ortalaması $(\overline{\mathrm{X}}=54.586)$, ikinci sınıftaki öğretmen adaylarının ortalaması 
$(\bar{X}=56.362)$, üçüncü sınıftaki öğretmen adaylarının ortalaması $(\bar{X}=57.092)$ ve dördüncü sınıftakilerin ortalaması ( $\overline{\mathrm{X}}=57.615)$ olarak tespit edilmiştir. Sınıf değişkenine göre sınıf yönetimi öz yeterlilik inançlarına ilişkin ortalamaların birbirine yakın olduğu söylenebilir.

Tablo 11.

Sinıf Değişkenine Göre SYÖYİ Tek Yönlü Varyans Analizi Sonuçlan

\begin{tabular}{llllrl}
\hline Varyansın Kaynağı & Kareler Toplamı & df & Kareler Ortalaması F & p \\
\hline Gruplar arası & 343.010 & 3 & 114.337 & 2.029 & 0.110 \\
Gruplar içi & 13580.500 & 241 & 56.351 & & \\
\hline
\end{tabular}

Sosyal bilgiler öğretmen adaylarının sınıf değişkenine göre sınıf yönetimi öz yeterlilik inançları arasında anlamlı bir fark olup olmadığını test etmek için yapılan tek yönlü varyans analizi testi sonuçlarına göre; 1 .sınıf öğrencilerinin ortalaması $(\bar{X}=$ 54.586), 2.sınıf öğrencilerinin ortalaması ( $\bar{X}=56.362)$, 3.sınıf öğrencilerinin ortalaması $(\bar{X}=57.092)$ ve 4 .sınıf öğrencilerinin ortalaması $(\bar{X}=57.615)$ arasında anlamlı bir fark görülmemiştir.

Sosyal bilgiler öğretmen adaylarının ÖMYT ile SYÖYİ arasındaki ilişkiyi gösteren basit doğrusal korelasyon sonucu Tablo 12' de gösterilmiştir.

Tablo 12.

ÖMYT İle SYÖYİ Arasındaki İlişki

\begin{tabular}{lcc}
\hline İlişki & Pearson's Correlations & $\mathbf{p}$ \\
\hline ÖMYT & 0.528 & $<.001$ \\
SYÖYİ & & \\
\hline
\end{tabular}

Sosyal bilgiler öğretmen adaylarının ÖMYT ile SYÖYİ arasında bir ilişki olup olmadığını test etmek için yapılan Pearson's basit doğrusal korelasyon testi sonucunda, sosyal bilgiler öğretmen adaylarının ÖMYT ile SYÖYİ arasında pozitif yönde anlamlı bir ilişki vardır $(\mathrm{r}=0.528, \mathrm{p}<0.001)$. Bu sonucun determinasyon katsayısı $(0.258)^{2}=0.27^{\prime}$ dir. Bu sonuca göre, sınıf yönetimi öz yeterlilik inançlarındaki değişimin \% 27'sini öğretmenlik mesleğine yönelik tutum açıklamaktadır (Can, 2016).

\section{Tartışma, Sonuç ve Öneriler}

Gerçekleştirilen araştırmada sosyal bilgiler öğretmenliği programını isteyerek tercih eden öğrencilerin ÖMYT, sosyal bilgiler öğretmenliği programını istemeyerek tercih eden öğrencilerin tutumlarına göre anlamlı bir şekilde arttığ1 görülmektedir. Dönmez ve Uslu'nun (2013) sosyal bilgiler öğretmen adaylarına yönelik çalışmasında, öğretmenlik mesleğini isteyerek tercih edenlerin, ÖMYT'leri boşta kalmamak, ÖSSLGS puanları ve anne baba telkini gibi nedenlerle öğretmenlik mesleğini seçenlere göre daha olumlu olduğu görülmektedir. Karatekin, Merey ve Keçe'nin (2015) sosyal bilgiler öğretmen adaylarına yönelik çalışmasında, öğretmenlik mesleğini istek üzerine seçen öğretmen adaylarının ÖMYT'leri öğretmenlik mesleğini isteksizlikle tercih eden sosyal bilgiler öğretmen adaylarına göre daha olumlu olduğu 
görülmektedir. Bu sonuçlara bakıldığında öğretmenlik mesleğini isteyerek tercih eden öğretmen adaylarının ÖMYT'lerinin olumlu olduğu söylenebilir.

Katılımcıların sınıf düzeylerine göre ÖMYT'leri arasında istatistikî olarak anlamlı bir farklılığın olmadığı görülmektedir. Karatekin, Merey ve Keçe'nin (2015) çalışmasında sınıf değişkenine göre sosyal bilgiler öğretmen adaylarının ÖMYT'lerinde anlamlı bir fark bulmamışken; Çiftçi ve Dikmenli (2015) sosyal bilgiler öğretmen adaylarının sınıf düzeylerine göre ÖMYT'lerinin değiştiğini tespit etmiştir. Farklı programlarda yapılan çalışmalara bakıldığında Çapa ve Çil, 2000; Çiçek Sağlam, 2008; Akpınar, Yıldız ve Ergin, 2006; Pektaş ve Kamer, 2011 sinıf düzeyleri ile öğretmenlik mesleğine yönelik tutum arasında anlamlı bir fark bulurken; Üstüner, Demirtaş ve Cömert, 2009; Bulut, 2011 sınıf düzeylerine göre öğretmenlik mesleğine yönelik tutumların farklılaşmadığını tespit etmişlerdir. Eğitim fakültesine başlayan bir öğrencinin sınıf düzeyi arttıkça öğretmenlik mesleğine yönelik tutumlarının anlamlı bir derecede artması beklenmektedir. Fakat bağlı bulunduğu fakülte ya da birimden memnun olmaması, programın beklentilerini karşılamamış olması ve zamana bağlı olarak öğretmenlik mesleğinin aslında kendi kişiliği için uygun olmadığını deneyimlemesi öğrencilerin mesleğe yönelik olumlu tutum geliştirmelerinin önünde bir engel olabilir.

Sosyal bilgiler öğretmenlik programını isteyerek tercih eden öğrencilerin SYÖYİ'nın sosyal bilgiler öğretmenliği programının istemeyerek tercih eden öğrencilerin sınıf SYÖTİlerinden anlamlı derecede daha yüksek olduğu görülmektedir. Ünlü, Kaşkaya ve Kızılkaya'da (2017) yapmış oldukları çalışmada benzer bulgulara ulaşmıştır. Bu çalışmaya göre, sosyal bilgiler öğretmenliğini isteyerek tercih eden öğretmen adaylarının sınıf yönetimi öz yeterlilik algıları, bölümü bilinçsizce seçen öğrencilerin öz yeterlilik algılarından istatistiksel olarak anlamlı düzeyde yüksek çıkmıştır. Bu sonuçlar, öğretmenlik mesleğini isteyerek seçen öğrencilerin SYÖYT'lerin daha yüksek olduğunu göstermektedir. Bu sonuçlar da gösteriyor ki bir kişinin bir mesleğe yönelik olumlu bir tutumu o kişinin meslek için gereken yeterliliklerini de olumlu olarak etkilemektedir.

Katılımcıların sınıf düzeylerine göre SYÖYİleri arasında istatistikî olarak anlamlı bir farklılığın olmadığı görülmektedir. Akkuş (2013), sosyal bilgiler öğretmen adaylarının SYÖYİ'lerine yönelik olarak yapmış olduğu çalışmasında, sosyal bilgiler öğretmen adaylarının sınıflara göre SYÖYÍlerinin değişmediği bulgusuna ulaşmıştır. Bu sonuçlardan hareketle, sınıf düzeyinin sınıf yönetimi öz yeterlilik inançlarında bir etkiye neden olmadığı söylenebilir. Hâlbuki öğrencilerin sınıf düzeyi arttıkça sınıf yönetimi öz yeterlilik inançlarının anlamlı bir derecede artması beklenir. Çünkü pedagojik bir eğitim alan bir öğrencinin sınıf düzeyi arttıkça mesleki yeterliliklerinin artması beklenmektedir. Sınıf yönetimi öz yeterlilik becerilerini de kapsayan mesleki yeterliliklerin artması doğal olarak sınıf yönetimi öz yeterlilik inançlarını da güçlendirecektir.

Sosyal bilgiler öğretmen adaylarının ÖMYT ile SYÖYİ arasında pozitif yönde anlamlı bir ilişki olduğu görülmektedir. Bu ilişkinin orta düzeyde olduğu ve determinasyon katsayısına göre yorumlandığında SYÖYİ 'nin\% 27'sini ÖMYT açıklamaktadır. Nakip ve Özcan (2016) öğretmen adaylarının öğretmenlik mesleğine yönelik öz yeterlilik inançları ile ÖMYT arasındaki ilişkiye bakmış ve bu ilişkinin orta düzeyde olduğu bulgusuna ulaşmıştır. Benzer bir çalışma Demirtaş, Cömert ve Özer 
(2011) tarafından da gerçekleştirilmiştir. Bu araştırmada öğretmen adaylarının öz yeterlilik inançları ile ÖMYT arasında pozitif fakat düşük düzeyde bir ilişki olduğu saptanmıştır. Bu sonuçlardan hareketle SYÖYI'lerin ve onu da kapsayan öğretmenlik mesleğine yönelik öz yeterlilik inançlarının öğretmenlik mesleğine yönelik tutuma olumlu bir katkı yaptığı anlaşılmaktadır.

Bu sonuçlardan hareketle bazı önerilerde bulunulmuştur.

- Birinci sınıftan itibaren öğrencilere öğretmenlik mesleğine yönelik olumlu tutum kazandiracak faaliyetler yapılabilir.

- Öğretmenlik mesleğine yönelik olumsuz tutuma sahip öğrencilerin neden olumsuz tutuma sahip oldukları araştırılabilir. Öğretmenlik mesleğini yapamayacağını düşünen öğrencilere rehberlik yapılarak merkezi yatay geçişle kendi kişiliğine, ilgi, istek ve kabiliyetine uygun başka bir mesleğe yönlendirilebilir.

- Öğrencilerin sınıf yönetimi öz yeterlilik inançlarının arttırılması için birinci sınıftan itibaren öğretmenlik uygulamasına ağırlık verilmeli ve öğrencilerin sınıf yönetiminde sorumluluk almaları özendirilmelidir.

- Bu çalışma, var olanı betimleyen bir çalışmadır. Fakat nicel araştırmalar konunun derinlemesine incelenmesinde bazı sınırlılıklara sahiptir. Bu nedenle konuyla ilgili nicel bulguları destelemek için nitel çalışmalarda yapılabilir.

- Bir öğretmen adayının süreç içerisindeki tutumları ve inançlarının değişip değişmediğini ya da hangi yönde değiştiğini tespit etmek amacıyla boylamsal araştırmalar yapılabilir.

- Bu çalışma Doğu Anadolu Bölgesinde yer alan iki üniversitenin sosyal bilgiler öğretmenliği programında gerçekleştirilmiştir. Benzer bir çalışma sosyal bilgiler öğretmenliği programı olan başka bölgelerde ve üniversitelerde gerçekleştirilebilir.

\section{Kaynakça}

Akkaya, N. (2009). Öğretmen adaylarının öğretmenlik mesleğine yönelik tutumlarının bazı değişkenlere göre incelenmesi. Dokuz Eylül Üniversitesi Buca Eğitim Fakültesi Dergisi, 3(25), 35-42.

Akkuş, Z. (2013). Sosyal bilgiler öğretmen adaylarının öz-yeterlilik inanç düzeylerinin belirlenmesi üzerine bir çalışma. Dicle Üniversitesi Ziya Gökalp Ĕ̈itim Fakültesi Dergisi, 20(2013), 102-116.

Aksoy, M. A. (2010). Öğretmen adaylarının öğretmenlik mesleğine ilişkin tutumları (Gaziosmanpaşa Üniversitesi Örneği). Sosyal Bilimler Araştırmaları Dergisi, 5(2), 197 - 212. https:/ / doi.org/10.19129/sbad.177

Arsal, Z. (2014). Mikro öğretimin öğretmen adaylarının sınıf yönetimi tutum ve inançlarına etkisi. Mersin Üniversitesi Eğitim Fakültesi Dergisi, 10(3), 137 - 150.

Balay, R. (2015). 2000'li Yıllarda Sını Yönetimi. (6.baskı). Ankara: Pegem Akademi.

Baykara Pehlivan, K. (2008). Sınıf öğretmeni adaylarının sosyo-kültürel özellikleri ve öğretmenlik mesleğine yönelik tutumları üzerine bir çalışma. Mersin Üniversitesi Ĕ̆itim Fakültesi Dergisi, 4(2), 151- 168.

Bulut, D. (2011). Müzik öğretmeni adaylarının öğretmenlik mesleğine yönelik tutumlar1. Gazi University Journal of Gazi Educational Faculty (GUJGEF), 31(3). 
Büyüköztürk, Ş., Çakmak, E. K., Akgün, Ö. E., Karadeniz, Ş., ve Demirel, F. (2014). Bilimsel araştırma yöntemleri. Pegem Akademi, Ankara.

Can, A. (2016). SPSS ile bilimsel araştırma sürecinde nicel veri analizi. (4.baskı). Ankara: Pegem Akademi.

Çapa, Y., ve Çil, N. (2000). Öğretmen adaylarının öğretmenlik mesleğine yönelik tutumlarının farklı değişkenler açısından incelenmesi. Hacettepe Üniversitesi Ĕ̈itim Fakültesi Dergisi, 10(18), 69 - 73.

Çetin, Ş. (2013). Öğretmen adaylarının sınıf yönetimi konusundaki öz yeterlilik inançlarını belirleme ölçeği (SYÖIÖ) geliştirme çalışması. Turkish Studies, 8 ( 12), 299 - 310. https:/ / doi.org/10.7827/TurkishStudies.5552

Çiçek Sağlam, A. (2008). Müzik öğretmenliği bölümü öğrencilerinin öğretmenlik mesleğine yönelik tutumları. Yüzüncü Yıl Üniversitesi Eğitim Fakültesi Dergisi, 5(1), 59-69.

Çifçi, T., ve Dikmenli, Y. (2015). Sosyal bilgiler öğretmen adaylarının öğretmenlik mesleğine ilişkin tutumları ve coğrafya alan bilgi düzeyleri. Journal of Educational Sciences (ISSN :2199-2053), 4,149-166

Demirtaş, H. (2012). Sınıf yönetiminin temelleri. Kıran, H. (Ed.). (7.baskı). Etkili Sınıf Yönetimi içinde (s. 1 - 34). Ankara: Anı Yayıncılık.

Demirtaş, H., Cömert, M., ve Özer, N. (2011). Öğretmen adaylarının öz-yeterlilik inançları ve öğretmenlik mesleğine yönelik tutumları. Eğitim ve Bilim, 36(159), $96-111$.

Dönmez, C., ve Uslu, S. (2011). Sosyal bilgiler öğretmen adaylarının öğretmenlik mesleğine yönelik tutumları. Türk Ĕ̆itim Bilimleri Dergisi, 11(1), 42 - 63.

Ekici, G. (2008). Sınıf yönetimi dersinin öğretmen adaylarının sınıf yönetimine yönelik tutum ve inanç kazanma düzeyine etkisi. Çukurova Üniversitesi Sosyal Bilimler Enstitüsü Dergisi, 17(3), 167 - 182.

Erden, M. (1998). Öğretmenlik mesleğine giriş. İstanbul: Alkım Yayınları.

George, D., and Mallery, M. (2003). Spss for windows step by step: a simple guide and reference 11.0 update (4.bs.). Boston: Pearson.

Green, S., and Salkind, N. (2005). Using spss for windows and macintosh: understanding and analysing data. Upper Saddle River, NJ: Prentice Hall.

Kahramanoğlu, R., Yokuş, E., Cücük, E., Vural, S., ve Şiraz, F. (2018). Öğretmenlik Mesleğine Yönelik Tutum Ölçeği (ÖMYTÖ) Geçerlilik ve güvenirlik çalışması. Turkish Studies Educational Science, 13(11), 1669 - 1686.

https://doi.org/10.7827/TurkishStudies.13561

Karasar, N. (2016). Bilimsel araştırma yöntemi: kavramlar, ilkeler, teknikler (30.bask1). Ankara: Nobel Yayınevi.

Karatekin, K., Merey, Z., ve Keçe, M. (2015). Sosyal bilgiler öğretmen adaylarının öğretmenlik mesleğine yönelik tutumları. Yüzüncü Yıl Üniversitesi Eğitim Fakültesi Dergisi, 22(1), 70 - 96.

Kılıç, S. (2016). Cronbach'ın alfa güvenirlik katsayısı. Journal of Mood Disorders, 6(1), 47 - 48. https://doi.org/10.5455/jmood.20160307122823

Kuran, K. (2002). Öğretmenlik mesleği (Niteliği ve Özellikleri). Türkoğlu, A. (Ed.). Öğretmenlik Mesleğine Giriş içinde (ss. 253 - 278). Ankara: Mikro Yayıncılık.

Nakip, C., ve Özcan, G. (2016). Öğretmen adaylarının öğretmenlik mesleğine yönelik öz-yeterlik inançları ile öğretmenlik mesleğine yönelik tutumları arasındaki 
ilişki. Mersin University Journal of the Faculty of Education, 12(3). https:// doi.org/10.17860/mersinefd.282380

Özder, H., Konedralı, G., ve Zeki, C. P. (2010). Öğretmen adaylarının öğretmenlik mesleğine yönelik tutumlarının çeşitli değişkenler açısından incelenmesi.

Kuram ve Uygulamada Egitim Yönetimi Dergisi, 16(2), 253-275.

Pektaş, M., ve Kamer, S. T. (2011). Fen bilgisi öğretmen adaylarının öğretmenlik mesleğine yönelik tutumları. Türk Eğitim Bilimleri Dergisi, 9(4), 829-850.

Sönmez, V., ve Alacapınar, F. (2017). Örneklendirilmiş bilimsel araştırma yöntemleri. Anı Yayıncılık, Ankara.

Şahin Sak, İ. T. (2015). Okul öncesi öğretmen adaylarının sınıf yönetimi ile ilgili özyeterlik inançları. Sakarya Üniversitesi Ĕ̆itim Fakültesi Dergisi, (29), 101 - 120.

Ünlü, İ., Kaşkaya, A., ve Kızılkaya, M. F. (2017). Sosyal bilgiler öğretmen adaylarının öz-yeterlilik inançlarının çeşitli değişkenler açısından incelenmesi. Ahi Evran Üniversitesi Kırşehir Ĕ̆itim Fakültesi Dergisi,18(2), 651 - 668.

Üstüner, M., Demirtaş, H., ve Cömert, M. (2010). Öğretmen adaylarının öğretmenlik mesleğine yönelik tutumları (İnönü Üniversitesi, Eğitim Fakültesi Örneği). Ĕgitim ve Bilim, 34(151), 140-155.

\section{Summary}

\section{Introduction}

At present, the traditional roles of the teachers are changing day by day. It is not possible for the teacher to have all the knowledge related to his/her field in a world where the quality and quantity of knowledge increase at an incredible rate. These days, the teachers are expected to be people who teach and guide learning rather than conveying what they know to the students. In order to do this, the teacher who guides the students must have a good understanding of the class structure and the classroom environment, have knowledge about their students and be able to manage them (Demirtaş, 2012). Pre-service teachers should be ready for these changing roles. Therefore, a pre-service teacher must have classroom management self-sufficiency. In order for the teachers to have self-sufficiency, they must also have the belief in classroom management self-sufficiency.

The studies related to the attitudes of pre-service teachers towards the teaching profession (Çapa and Çil, 2000; Akkaya, 2009; Aksoy, 2010; Özder, Konedralı and Perkan Zeki, 2010) and the studies on the attitudes of specifically pre-service social studies teachers towards the teaching profession (Dönmez ve Uslu, 2013; Ünlü, Kaşkaya ve Kızılkaya, 2017) are available in the literature review conducted to reveal the importance of the research. When the literature is examined again, it is observed that there are studies that measure the classroom management self-sufficiency beliefs or perceptions of pre-service teachers (Ekici, 2008; Arsal, 2014; Şahin Sak, 2015). However, a study measuring the classroom management self-sufficiency beliefs of preservice social studies teachers has not been encountered. Moreover, there is no research that measures the correlation between the attitudes of pre-service social studies teachers towards teaching profession and their self-sufficiency beliefs in classroom management. Considering that classroom management self-sufficiency beliefs are accepted as an important variable in the success of a teacher, and 
considering that attitude towards teaching profession is accepted as an important predictor of classroom management self-sufficiency beliefs, it is important to carry out such a study. In this context, the problem of the research consists of the attitudes of pre-service social studies teachers towards teaching profession and their classroom management self-sufficiency beliefs.

\section{Method}

The research was carried out in correlational survey model, one of the quantitative research designs. The population of the research consists of the pre-service social studies teachers studying in Social Studies Education disciplines of higher education institutions in Turkey. Considering the accessibility in making the sampling selection, the universities in the Eastern Anatolia Region were included in the study. In this respect, by carrying out the typical case sampling, one of the purposeful sampling methods, among these universities, the sampling of this study consists of the preservice teachers studying in the social studies teaching program at Muş Alparslan University and Frrat University in Eastern Anatolia Region during the fall semester of the 2019-2020 academic year.

The Attitude Scale towards Teaching Profession generated by Kahramanoğlu, Yokuş, C1şık, Vural and Şiraz (2018) was applied in this research so as to measure the attitudes of pre-service social studies teachers towards the teaching profession. This scale, generated for the pre-service teachers, explains $57.597 \%$ of the total variance. The classroom management self-sufficiency beliefs scale of pre-service teachers developed by Çetin (2013) was conducted in order to measure the classroom management selfsufficiency beliefs of pre-service social studies teachers.

Since the data obtained from the attitude scale towards the teaching profession were not distributed normally, whereas the Mann-Whitney $U$ test was applied to test whether there was a significant difference in the attitudes of the pre-service social studies teachers towards the teaching profession according to whether they willingly prefer the teaching profession, Kruskal-Wallis test was used to test whether there was a differentiation according to year of study. Because the data acquired from the classroom management self-sufficiency beliefs scale were normally distributed and provided the condition that variances are homogeneous, unrelated samples t-test was applied to determine the presence or absence of a significant differentiation among the classroom management self-sufficiency beliefs according to whether pre-service social studies teachers voluntarily prefer the teaching profession, and one-way analysis of variance (ANOVA) test was carried out to test the presence or absence of a differentiation according to the grade variable. Simple linear correlation test was used to test whether there was a correlation between the attitudes of pre-service teachers towards the teaching profession and their classroom management self-sufficiency beliefs.

\section{Findings}

In the descriptive statistics results of the attitudes of pre-service teachers towards the teaching profession according to whether they voluntarily prefer the teaching profession or not, there is no obvious difference in the attitude towards the teaching profession between the pre-service teachers who prefer and do not prefer the social studies teaching program voluntarily. According to the results of the Mann-Whitney 
$\mathrm{U}$ test conducted to test whether there was a significant difference in the attitudes of the pre-service social studies teachers towards the teaching profession according to whether they willingly prefer the teaching profession, the attitudes of the students who voluntarily prefer social studies teaching program towards the teaching profession differ significantly from the attitudes of the students who do not voluntarily prefer the social studies teaching program towards the teaching profession. According to the results of descriptive statistics carried out to determine the attitudes of the preservice social studies teachers towards the teaching profession according to the grade variable, it can be said that there were similar averages in the attitude towards the teaching profession between the years of study, and therefore the grade variable is not effective in the attitude towards the teacher. According to the results of Kruskal-Wallis test conducted in order to determine whether there is a significant difference between the attitudes of the pre-service social studies teachers towards the teaching profession according to the grade variable, the grade variable does not make a significant difference on the attitudes towards the teaching profession. According to the results of unrelated samples $t$ test conducted to test whether there was a significant difference between classroom management self-efficacy beliefs of the pre-service social studies teachers according to whether they voluntarily prefer the social studies teaching program or not, there was a significant difference between the classroom management self-sufficiency beliefs $\left(X^{-}=57.073\right)$ of the pre-service social studies teachers who voluntarily preferred the social studies teaching program and the classroom management self-sufficiency beliefs $\left(X^{-}=54.988\right)$ of the pre-service social studies teachers who did not voluntarily prefer the social studies teaching program. According to the results of the one-way analysis of variance (ANOVA), which was conducted to test whether there was a significant difference between the classroom management self-efficacy beliefs of pre-service social studies teachers according to the grade variable, there was no significant difference between the grade variables. According to the simple linear correlation test conducted to reveal whether there was a correlation between the attitudes of the pre-service social studies teachers towards teaching profession and their classroom management self-sufficiency beliefs, it was observed that there was a positive significant correlation between the attitudes of the pre-service social studies teachers towards teaching profession and their classroom management self-sufficiency beliefs.

\section{Results}

In the research, it is concluded that the attitudes of the students, who voluntarily prefer the social studies teaching program, towards the teaching profession are significantly higher than the attitudes of the students, who do not voluntarily prefer social studies teaching program. It is also observed that there is no statistically significant difference between the attitudes of the pre-service social studies teachers towards the teaching profession according to their year of study. In addition, it is seen that the classroom management self-sufficiency beliefs of the students, who voluntarily prefer social studies teaching program are significantly higher than the classroom management self-sufficiency beliefs of the students, who do not voluntarily prefer social studies teaching program. Besides, it is determined that there is no statistically significant difference between the classroom management self-sufficiency beliefs of the pre- 
service social studies teachers according to the grade variable. It is concluded that there is a positive significant correlation between the attitudes of the pre-service social studies teachers towards teaching profession and their classroom management selfsufficiency beliefs. This correlation is at a medium level, and when interpreted according to the determination coefficient, the attitude towards teaching profession explains $27 \%$ of classroom management self-sufficiency beliefs.

\section{Discussion}

According to the results, pre-service teachers who voluntarily prefer the teaching profession have higher classroom management self-sufficiency beliefs. Based on these results, it can be stated that the grade level does not have an effect on classroom management self-sufficiency beliefs. However, as the grade level of students increases, their classroom management self-efficacy beliefs are expected to increase significantly because the students who have pedagogical education are expected to increase their professional competences as the grade level increases. The increase in professional competences including classroom management self-sufficiency competence is naturally expected to strengthen the classroom management self-sufficiency beliefs.

In this study, it was found that there is a positive but low level correlation between self-sufficiency beliefs of pre-service teachers and their attitudes towards teaching profession. Based on these results, it is understood that the classroom management self-sufficiency beliefs and self-sufficiency beliefs towards the teaching profession that encompasses it make a positive contribution to the attitude towards the teaching profession.

\section{Pedagogical Implications}

This study is a work that describes what exists. However, quantitative research has some limitations in the in-depth study of the subject. For this reason, it can be done in qualitative studies to support quantitative findings on the subject. In order to contribute to the field, longitudinal studies can be conducted to determine whether the prospective teachers' attitudes and beliefs in the process have changed or in which direction they have changed. Also, since this study was carried out in the social studies teaching program of two universities in the Eastern Anatolia Region, a similar study can be carried out in other regions and universities with social studies teaching program.

\section{Araştırmanın Etik Taahhüt Metni}

Yapılan bu çalışmada bilimsel, etik ve alıntı kurallarına uyulduğu; toplanan veriler üzerinde herhangi bir tahrifatın yapılmadığı, karşılaşılacak tüm etik ihlallerde "Cumhuriyet Uluslararası Eğitim Dergisi ve Editörünün" hiçbir sorumluluğunun olmadığ1, tüm sorumluluğun Sorumlu Yazara ait olduğu ve bu çalışmanın herhangi başka bir akademik yayın ortamına değerlendirme için gönderilmemiş olduğu sorumlu yazar tarafından taahhüt edilmiştir.

\section{Authors' Biodata/ Yazar Bilgileri}


Zafer ÇAKMAK Fırat Üniversitesi Türkçe ve Sosyal Bilimler Anabilim Dalı Sosyal Bilgiler Eğitimi Alanında Profesör Doktor olarak görev yapmaktadır.

Zafer Çakmak is working as a Professor Doctor in the Department of Turkish and Social Sciences Education, Social Studies Education at Firat University.

Cengiz TAŞKIRAN Muş Alparslan Üniversitesi Türkçe ve Sosyal Bilimler Anabilim Dalı Sosyal Bilgiler Eğitimi Alanında Doktor Öğretim Üyesi olarak görev yapmaktadir.

Cengiz Taşkıran is working as a Assistant Professor in the Department of Turkish and Social Sciences Education, Social Studies Education at Muş Alparslan University.

İrfan ARIKAN Harran Üniversitesi Türkçe ve Sosyal Bilimler Anabilim Dalı Sosyal Bilgiler Eğitimi Alanında Araştırma Görevlisi olarak görev yapmaktadır.

Irfan Arrkan is working as a Research Assistant in the Department of Turkish and Social Sciences Education, Social Studies Education at Harran University. 